\title{
Cast Iron Machine Tool Body Analysis: The Theoretical and Experimental Approach
}

\author{
Norbert Kepczak ${ }^{1} \cdot$ Witold Pawlowski ${ }^{1}$
}

Received: 20 February 2017 / Accepted: 11 September 2018/ Published online: 18 September 2018

(C) The Author(s) 2018

\begin{abstract}
The paper presents theoretical and experimental modal analysis of the machine tool lathe body made of cast iron. Modal analysis is commonly used in practice as a technique for determining the dynamic properties of objects. The aim of the work was to compare the theoretically obtained results with experimental research. The modal analyses both theoretical and experimental were conducted in frequency domain in range from 0 to $1600 \mathrm{~Hz}$. Results from theoretical modal analysis were highly convergent with experimental studies. This verification of theoretical model with experimental results gave justified basis to conduct the research based on verified model. The model could be subsequently applied to perform simulations of the analyzed body behavior in the conditions which were not examined experimentally. On this basis, the conclusions about dynamic behavior of the analyzed object were formulated.
\end{abstract}

Keywords Modal analysis - Dynamic properties - Machine tool body $\cdot$ Cast iron

\section{Introduction}

Bodies are elements of machine tools which connect basic assemblies and mechanisms into a whole structure. Their role is to keep the other parts and assemblies of a machine tool in a specific mutual position. Generally, the machine tool consists of the main body, being the primary support structure and a few to a dozen of smaller bodies, which are bolted to the main body and constitute a whole machine tool. Most of the machine tool bodies are made of gray cast iron or modified cast iron (Lopez de Lacalle 2009).

Cast iron is a high carbon alloy of iron with carbon. It usually contains alloy additives such as silicon, manganese, phosphorus or sulfur also. Cast iron contains from 2.06 to $6.67 \%$ carbon in the form of cementite or graphite. The occurrence of a particular phase of carbon depends on the cooling rate and chemical composition of the alloy. One of

Witold Pawlowski

witold.pawlowski@p.lodz.pl

Norbert Kepczak

norbert.kepczak@p.lodz.pl

1 Institute of Machine Tools and Production Engineering, Faculty of Mechanical Engineering, Lodz University of Technology, Stefanowskiego 1/15, 90-924 Lodz, Poland the types of cast iron is gray cast iron wherein the carbon is present as graphite. Its name comes from the fact that this breakthrough is gray. It is regarded as the cast iron of higher quality and is more ductile, easily treatable, has a good fluidity and has a smaller shrinkage casting-(around $1.0 \%)$ than the white cast iron. It is used to make bodies, housings, blocks of pumps, compressors and motors although it is more brittle and susceptible to cracking than steel (Kostyleva et al. 2008).

Modal analysis is the process of determining the inherent dynamic characteristics of a system in the form of natural frequencies, damping factors and mode shapes, and using them to formulate a mathematical model for its dynamic behavior. It has been successfully applied to solve structural dynamic problems in mechanical (Matsuo et al. 1986; Li et al. 2013; Zaghbani et al. 2009; Zhang et al. 2003; Gagnol et al. 2011) and aeronautical (Vivo et al. 2013) engineering. Recently, modal analysis has also found its broad applications for civil and building (Rahmatalla et al. 2014) structures, biomechanical and harvest (Ebrahimi et al. 2013) problems, space structures, electrics and electronics (Brecher et al. 2014) acoustical instruments (Chomette et al. 2015), transportation (Nangolo et al. 2014) and nuclear plants (Park et al. 2014). As a result of modal analysis, the modes, their natural frequencies and damping 
ratios are given. Knowledge of these parameters enables prediction of the behavior of an object due to any imbalances. Modal analysis is used for modifying the structure, diagnostics of condition of the structure, the synthesis of control systems of active vibration reduction as well as the verification and validation of numerical models such as finite element and boundary element models (Źółtowski 2002).

In machine tool field, modal analysis technique is also very often applied. Research has been conducted both on whole structures of machine tools and on the particular parts. A cylindrical grinding machine (Barzegar et al. 2013), milling machine (Pedrammehr et al. 2012) and moving table of 4-DOF parallel machine tool (Mahboubkhah et al. 2017) were investigated. Mode shapes and natural frequencies were compared. The research has shown that there was a very high similarity of FEM studies in comparison with experimental tests.

This paper presents the modal analysis which was conducted in order to compare the results of the dynamic properties of the theoretical simulations with experimental research of machine tool lathe bed made of cast iron. The comparison was carried out to verify the theoretical modal model and obtain the confirmation of assumptions regarding this model material and structural properties.

\section{Theoretical Modal Analysis}

Theoretical modal analysis is based on the physical model of the dynamic system with its mass stiffness and damping properties (Źółtowski 2002). The theoretical modal analysis requires solving the system of differential equations for the assumed structural model of the construction. So achieved sets of free vibration frequencies, damping coefficients and modes of vibrations allow the structural behavior to be simulated at any extortion, selection of controls, design modifications and other. Theoretical modal analysis is used in the design process, when there is no possibility to conduct the experimental research on the real object (Żółtowski 2002).

To conduct the theoretical modal analysis, the 3D model of the machine tool body was created in Autodesk Inventor environmental. It is the bed of the lathe which is produced by Koluszki Foundry and Machinery. Its dimensions are $300 \mathrm{~mm} \times 300 \mathrm{~mm} \times 2000 \mathrm{~mm} \quad$ (height $\times$ width $\times$ length). The body is made of gray cast iron (Fig. 1).

During investigation, the theoretical modal analyses have been conducted in frequency domain up to $1600 \mathrm{~Hz}$. The mechanical properties of the structural material used in the analyses are presented in Table 1.

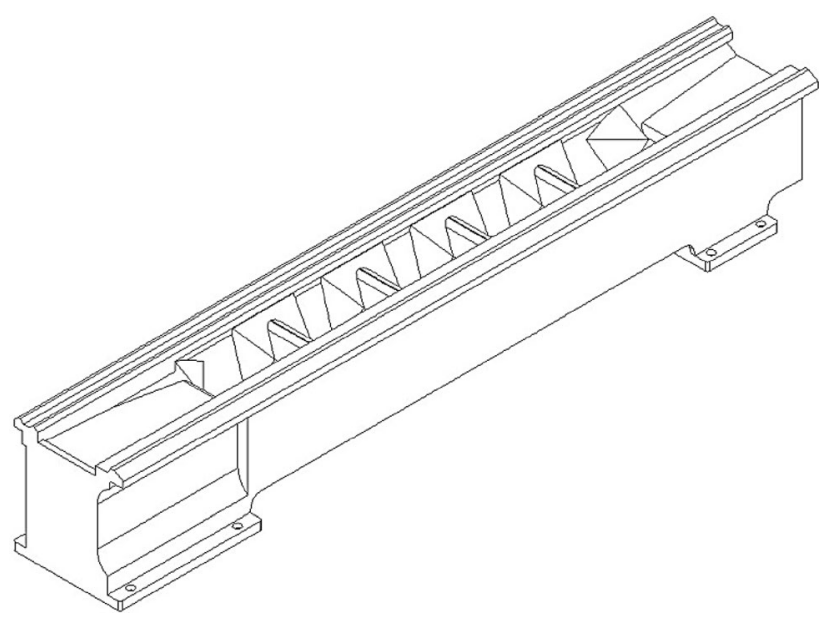

Fig. 1 Isometric view of the machine tool bed

Table 1 Mechanical properties of cast iron

\begin{tabular}{ll}
\hline & Cast iron $^{\mathrm{a}}$ \\
\hline Tensile strength (MPa) & 997 \\
Compressive strength (MPa) & - \\
Young's modulus (GPa) & 168 \\
Poisson's ratio (一) & 0.29 \\
Kirchhoff's modulus (MPa) & 64,900 \\
Density $\left(\mathrm{g} / \mathrm{cm}^{3}\right.$ ) & 7.15 \\
\hline
\end{tabular}

${ }^{\mathrm{a}}$ Mechanical properties of cast iron are taken from the materials library of Autodesk Inventor

Boundary conditions definition is a very important aspect during the analysis. On the left and right side of the body, there are 8 ( 4 on both sides of the body) mounting holes, through which the bed is mounted to the basement. The model has been fixed with these mounting holes'

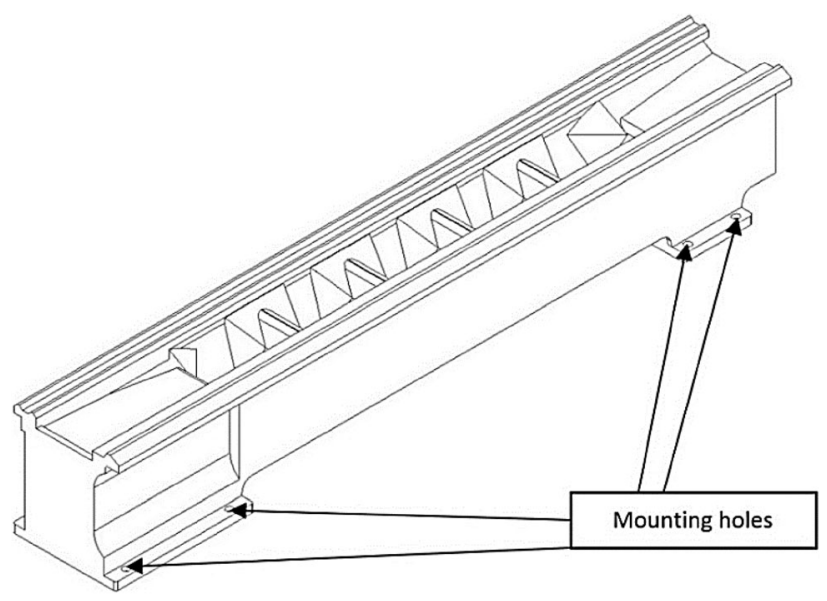

Fig. 2 Places of fixing the body 
cylinders (Fig. 2) which has blocked movement in all directions.

The finite elements mesh setting is another very important problem during the analysis. The smaller the size of the mesh element the more elements, nodes and number of equations that have to be solved. In the case of smaller elements, the time of meshing was longer, but the results were more accurate. Figure 3 shows the view of a mesh of the cast iron body. The cast iron body mesh consists of 475,499 nodes and 277,603 elements.

Having defined all necessary settings, the theoretical modal analysis was carried out. Results of simulations are presented in Table 2. Modes of vibrations were marked from F1 to F20.

On that level of research it was hard to indicate the importance of the modes and their influence on the body behavior. All the modes were regarded as equally possible to extort because in theoretical model analysis, the damping coefficients of certain modes are not calculated.

\section{Experimental Modal Analysis}

Experimental modal analysis is a technique often used in practice to study dynamic properties of mechanical objects, both during the construction and during operation of the machinery. Identification experiment in the experimental modal analysis involves extorting the vibration of the object, with simultaneous measurement of the extorting force and the response of the system, usually in the form of the spectrum of vibrations acceleration (Źółtowski 2002).

Procedure of the experimental modal analysis can be realized by single input single output (SISO), single input multiple outputs (SIMO) and multiple inputs multiple outputs (MIMO) techniques. These methods are different not only in the requirements of measuring devices, but also

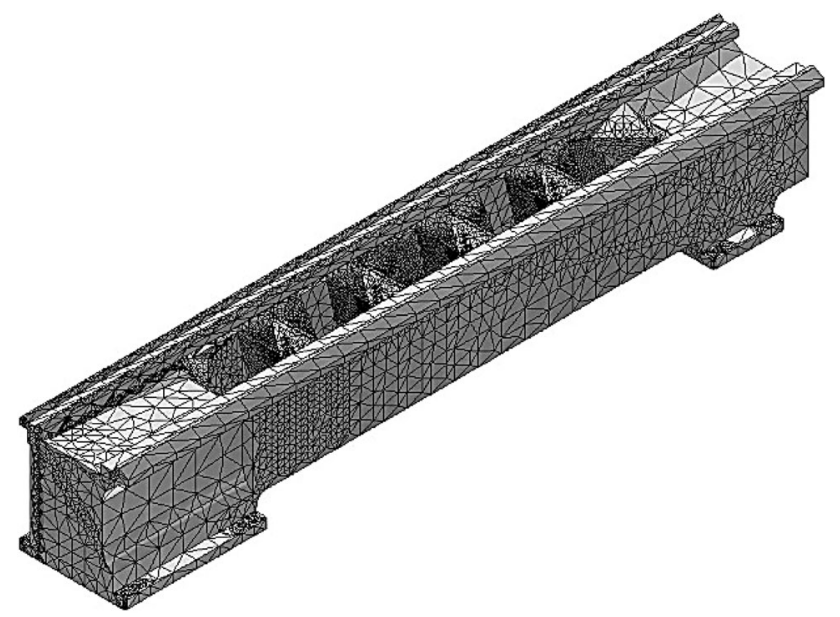

Fig. 3 View of a mesh of the cast iron body the requirements for research and accuracy of results of the analysis.

SISO method is mainly used for two-channel data acquisition system, and when the frequency response function (FRF) may be limited to a few measurement points. It is usually used during the modal hammer test. (Excitation is input signal when the acceleration is output signal.) This method can be used in two options: first as a roving hammer (fixed accelerometer) and second as fixed hammer (roving accelerometer). In practice, the first method is easier to carry out because there is no need to change fixing place of the accelerometer from one measurement point to another. The problem can appear during normalization of the input signal from several measurement points; therefore, in this case the procedure of averaging must be used.

SIMO method enables using the harmonic exciter as the input signal generator for simultaneously extorting many points. In this method, multi-channel card of data acquisition system is required. In this case, the results are more accurate because the same signal of the extortion is used for all answers of the points of analysis during the modal analysis.

MIMO method is more hardware demanding but returns more accurate information of the analyzed system than SISO or SIMO. It is usually used when the multi-channel data acquisition system is available. Selected points can be extorted with different force characteristics in order to increase the accuracy and effectiveness of the modal analysis.

In further analysis, the SISO method was used because the number of measurement points was considerably reduced.

In order to conduct the experimental modal analysis, it was necessary to model the tested element in the Pulse LabShop program (Fig. 4). The geometry model of the analyzed machine tool body is required in the experimental modal analysis system in order to properly plan and carry out the experiments and to determine the modes of vibrations and their graphic representation.

The experimental modal analysis was carried out for transversal, longitudinal and vertical directions. The signal of the force course from the modal hammer and the acceleration signal from the accelerometer sensor were collected and processed in the Pulse data acquisition system. A Pulse Lite package from Brüel and Kjær was used including: a 3560L measurement module, a 2 channels FFT analysis program, a 4514 acceleration sensor and a modal hammer type 8206-003. The coherence function was determined by means of the Pulse LabShop system on the basis of five repetitions of the excitation. The scheme of a measuring stand is shown in Fig. 5. During the research, the body was mounted to the ground by mounting holes 
Table 2 Results of the theoretical modal analysis

\begin{tabular}{lcccccccccc}
\hline Mode & F1 & F2 & F3 & F4 & F5 & F6 & F7 & F8 & F9 & F10 \\
\hline Frequency of the body $(\mathrm{Hz})$ & 189 & 333 & 364 & 393 & 477 & 510 & 593 & 765 & 861 & 902 \\
\hline Mode & F11 & F12 & F13 & F14 & F15 & F16 & F17 & F18 & F19 & F20 \\
\hline Frequency of the body $(\mathrm{Hz})$ & 1016 & 1079 & 1107 & 1136 & 1198 & 1258 & 1267 & 1357 & 1383 & 1438 \\
\hline
\end{tabular}

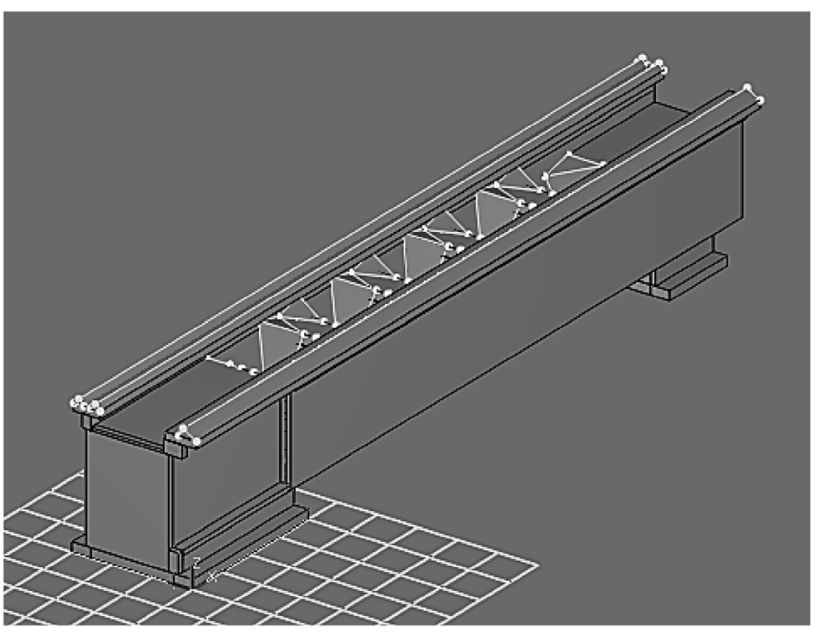

Fig. 4 Model of the body in Pulse LabShop program

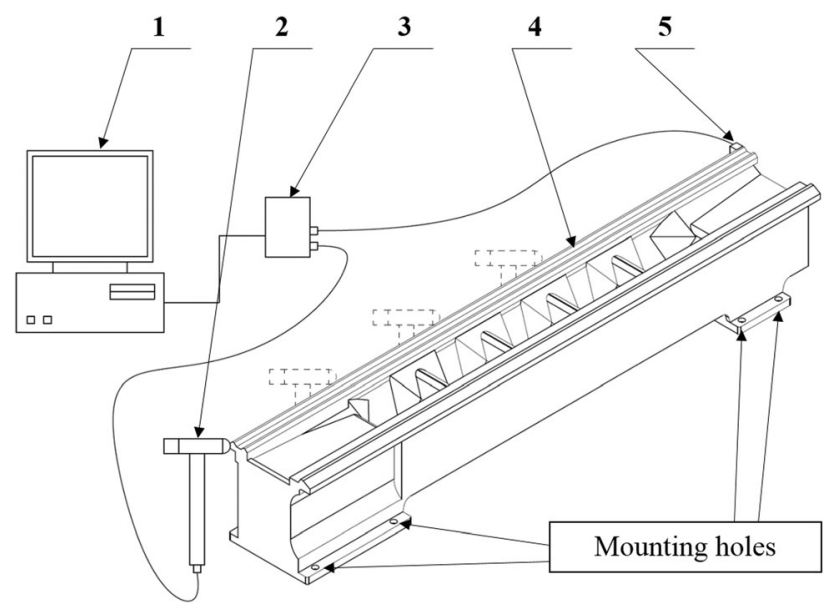

Fig. 5 The scheme of testing stand: 1 -computer, 2 -modal hammer, 3-data system acquisition, 4-machine tool body, 5-accelerometer

located on both sides of the bed. Experimental modal analysis was carried out in frequency domain up to $1600 \mathrm{~Hz}$, similar to theoretical modal analysis. For the analysis 75 points in transversal direction, 77 points in longitudinal direction and 45 points in vertical direction were chosen for excitation, which are presented in Fig. 6. Location of acceleration sensor is presented in Fig. 7. The body was tested three times. Results of the experimental modal analysis are presented in Tables 3, 4 and 5.

\section{Results and Discussion}

After the research summary of the results has been prepared, for comparison analysis the modes which can appear in reality were chosen (those of experimental results).

The first characteristic mode (one half-wave in transversal direction) appears at frequency of about $200 \mathrm{~Hz}$. In the case of theoretical analysis, it was $189 \mathrm{~Hz}$, when the frequency of experimental analysis was $211 \mathrm{~Hz}$. Figures 8 and 9 show modes of free vibrations of theoretical and experimental modal analysis.

Second analyzed mode (one half-wave in vertical direction) appears at frequency of about $340 \mathrm{~Hz}$. In the case of theoretical analysis, it was $364 \mathrm{~Hz}$, when the frequency of experimental analysis was $322 \mathrm{~Hz}$. Figures 10 and 11 show modes of free vibrations of theoretical and experimental modal analysis.

Third analyzed mode (two half-waves in transversal direction) appears at frequency of about $400 \mathrm{~Hz}$. In the case of theoretical analysis, it was $393 \mathrm{~Hz}$, when the frequency of experimental analysis was $365 \mathrm{~Hz}$. Figures 12 and 13 show modes of free vibrations of theoretical and experimental modal analysis.

Fourth analyzed mode (two half-waves in vertical direction and parallel vibrations in longitudinal direction) appears at frequency of about $500 \mathrm{~Hz}$. In the case of theoretical analysis, it was $477 \mathrm{~Hz}$, when the frequency of experimental analysis was $529 \mathrm{~Hz}$. Figures 14 and 15 show modes of free vibrations of theoretical and experimental modal analysis.

Mode in the shape of three half-waves in transversal direction appears at frequency of about $750 \mathrm{~Hz}$. In the case of theoretical analysis, it was $765 \mathrm{~Hz}$, when the frequency of experimental analysis was $756 \mathrm{~Hz}$. Figures 16 and 17 show modes of free vibrations of theoretical and experimental modal analysis.

Last mode in the shape of three half-waves in vertical direction and opposite vibrations in longitudinal direction appears at frequency of about $1000 \mathrm{~Hz}$. In the case of theoretical analysis, it was $1016 \mathrm{~Hz}$, when the frequency of experimental analysis was $975 \mathrm{~Hz}$. Figures 18 and 19 show modes of free vibrations of theoretical and experimental modal analysis. 
Fig. 6 View of net of the excited points $\mathbf{a}$ in transversal direction, $\mathbf{b}$ in longitudinal direction $\mathbf{c}$ in vertical direction a

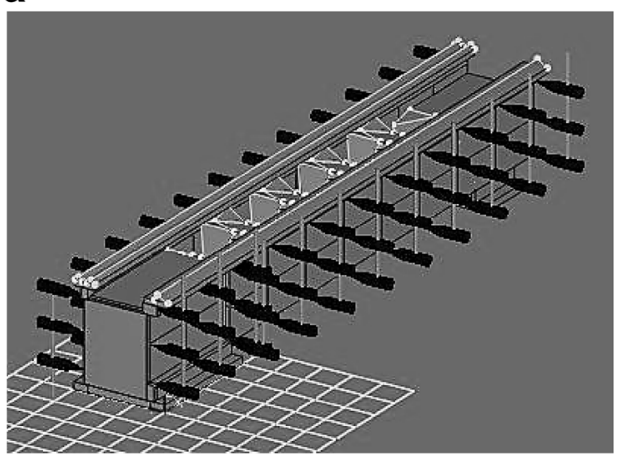

b

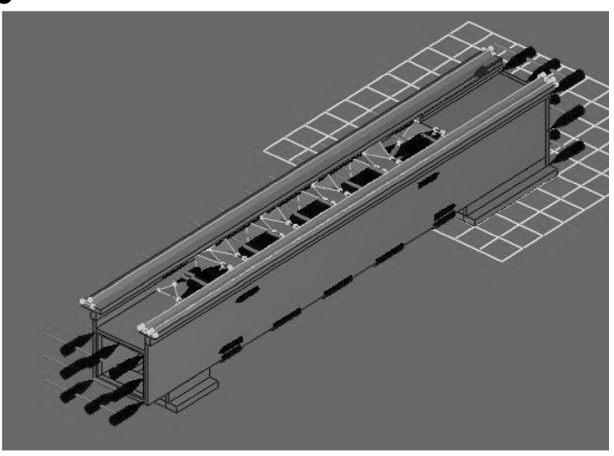

c
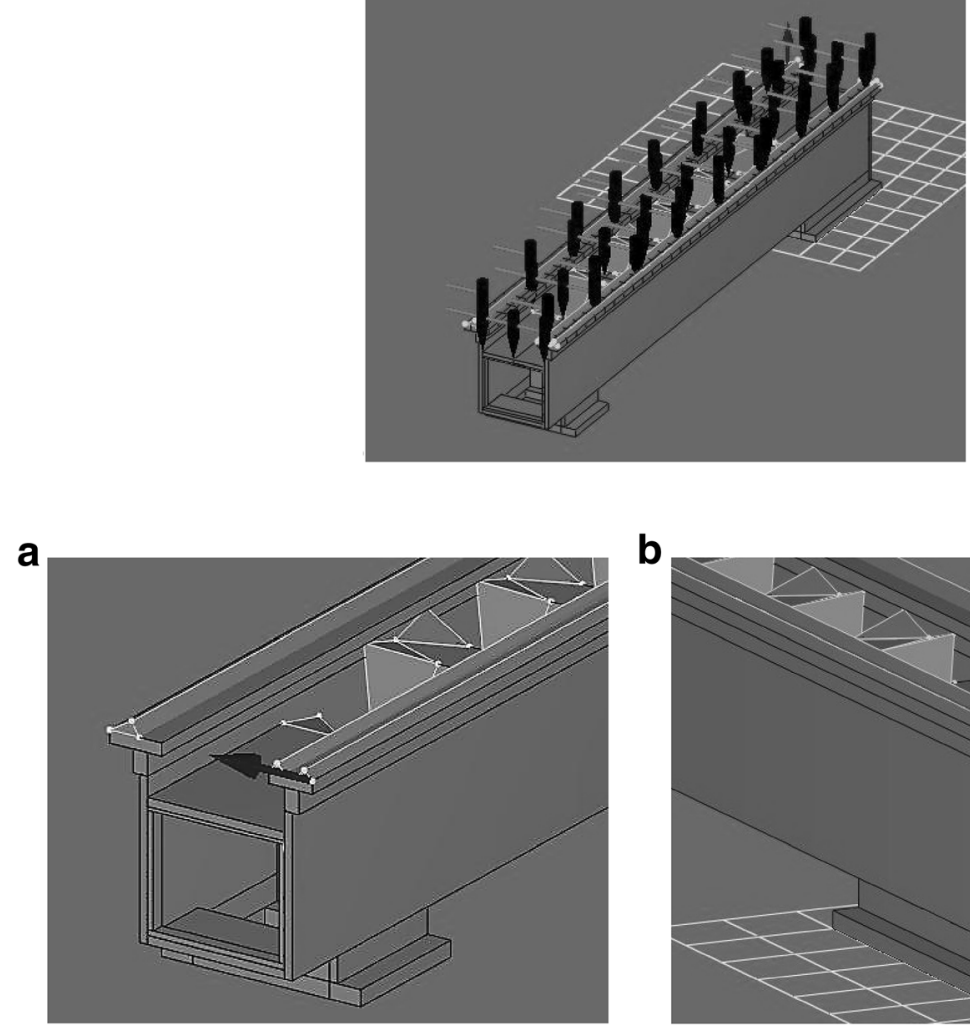

Fig. 7 View of the points of acceleration sensor fixing $\mathbf{a}$ in transversal direction, $\mathbf{b}$ in longitudinal direction $\mathbf{c}$ in vertical direction b

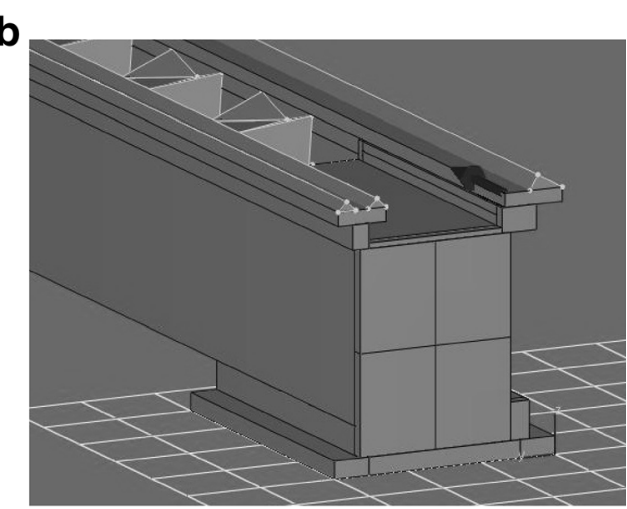

C

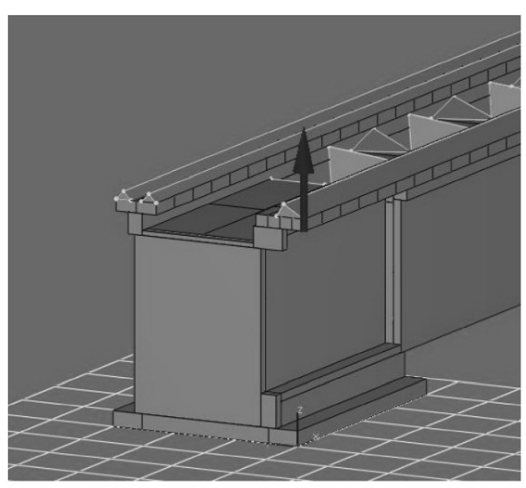


Table 3 Results of the experimental modal analysis for transversal direction
Table 4 Results of the experimental modal analysis for longitudinal direction

\begin{tabular}{lcccc}
\hline & Measurement $1(\mathrm{~Hz})$ & Measurement 2 $(\mathrm{Hz})$ & Measurement 3 $(\mathrm{Hz})$ & Average $(\mathrm{Hz})$ \\
\hline$F_{\text {trans }} 1$ & 43 & 42 & 43 & 42.67 \\
$F_{\text {trans }} 2$ & 126 & 125 & 127 & 126.00 \\
$F_{\text {trans }} 3$ & 211 & 212 & 210 & 211.00 \\
$F_{\text {trans }} 4$ & 367 & 363 & 366 & 365.33 \\
$F_{\text {trans }} 5$ & 422 & 421 & 422 & 421.67 \\
$F_{\text {trans }} 6$ & 754 & 758 & 756 & 756.00 \\
$F_{\text {trans }} 7$ & 910 & 905 & 908 & 907.67 \\
$F_{\text {trans }} 8$ & 1182 & 1183 & 1182 & 1182.33 \\
$F_{\text {trans }} 9$ & 1493 & 1483 & 1484 & 1483.33 \\
$F_{\text {trans }} 10$ & 1504 & 1501 & 1502 & 1502.33 \\
\hline
\end{tabular}

\begin{tabular}{lllll}
\hline & Measurement 1 $(\mathrm{Hz})$ & Measurement 2 $(\mathrm{Hz})$ & Measurement 3 $(\mathrm{Hz})$ & Average $(\mathrm{Hz})$ \\
\hline$F_{\text {long }} 1$ & 529 & 528 & 529 & 528.67 \\
$F_{\text {long }} 2$ & 914 & 914 & 915 & 914.33 \\
$F_{\text {long }} 3$ & 976 & 975 & 974 & 975.00 \\
\hline
\end{tabular}

Table 5 Results of the experimental modal analysis for vertical direction

\begin{tabular}{lllll}
\hline & Measurement $1(\mathrm{~Hz})$ & Measurement 2 $(\mathrm{Hz})$ & Measurement 3 $(\mathrm{Hz})$ & Average $(\mathrm{Hz})$ \\
\hline$F_{\text {vert }} 1$ & 125 & 125 & 126 & 125.33 \\
$F_{\text {vert }} 2$ & 322 & 322 & 321 & 321.67 \\
$F_{\text {vert }} 3$ & 427 & 425 & 427 & 426.33 \\
$F_{\text {vert }} 4$ & 529 & 529 & 530 & 529.33 \\
$F_{\text {vert }} 5$ & 728 & 729 & 729 & 728.67 \\
$F_{\text {vert }} 6$ & 976 & 975 & 974 & 975.00 \\
\hline
\end{tabular}

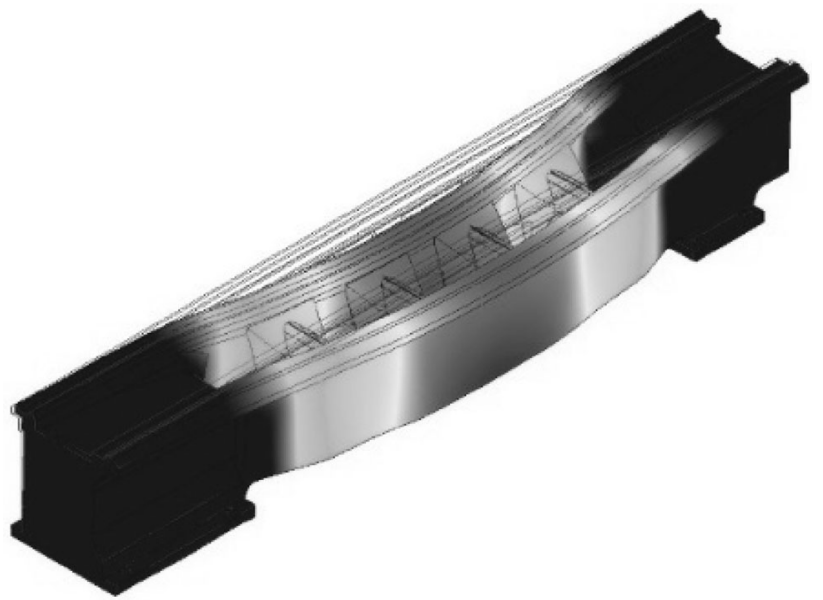

Fig. 8 Mode of frequency $189 \mathrm{~Hz}$ (theoretical modal analysis)

Table 6 and Fig. 20 have presented a comparison of the results obtained in theoretical and experimental ways.

Results of theoretical and experimental modal analysis demonstrate very high similarity considering modes of free vibrations and frequencies. In order to update model accuracy, the convergence analysis was carried out. During

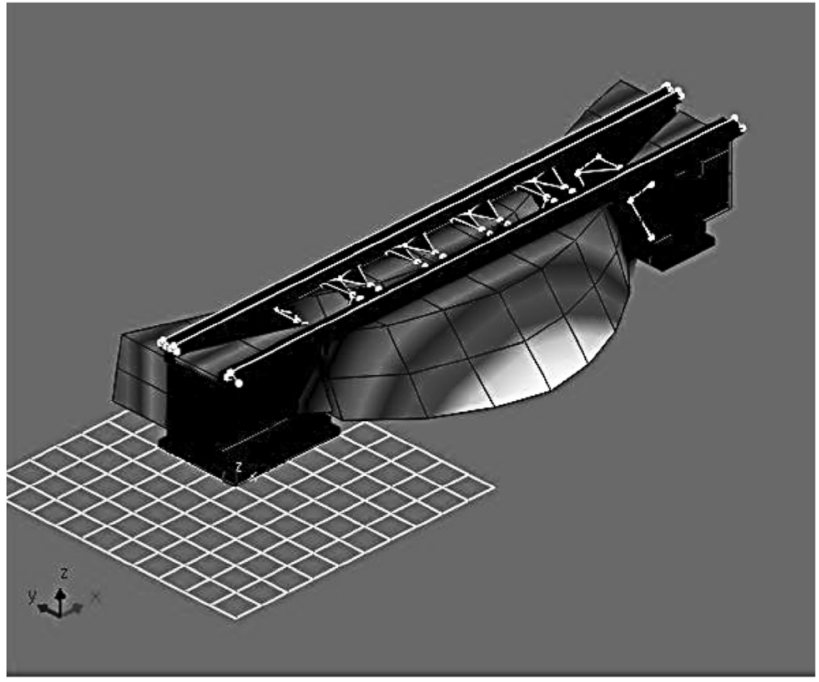

Fig. 9 Mode for frequency $211 \mathrm{~Hz}$ (experimental modal analysis)

analysis, the meshing net has been smoothed six times that resulted in improving the results of the simulation with the relative error between the following smoothing steps at the level of $0.1 \%$. 


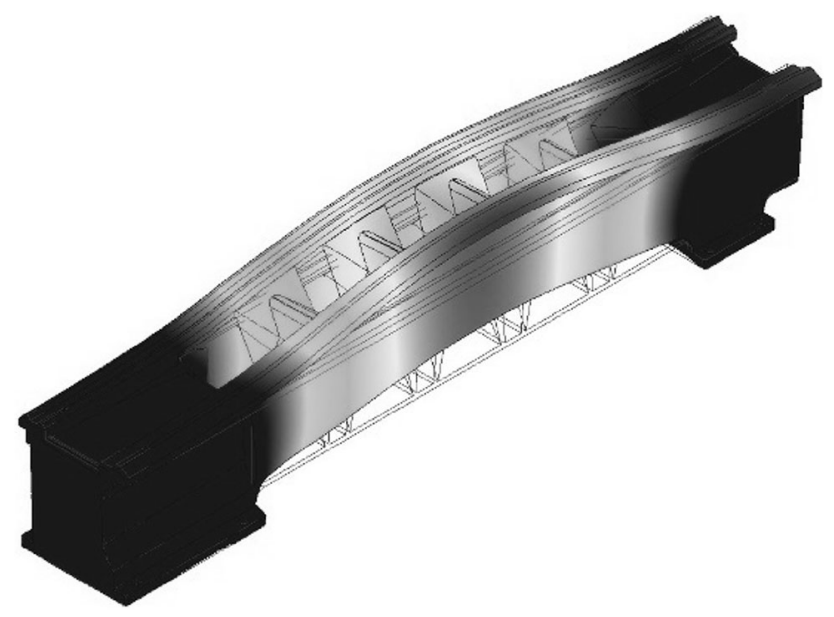

Fig. 10 Mode of frequency $364 \mathrm{~Hz}$ (theoretical modal analysis)

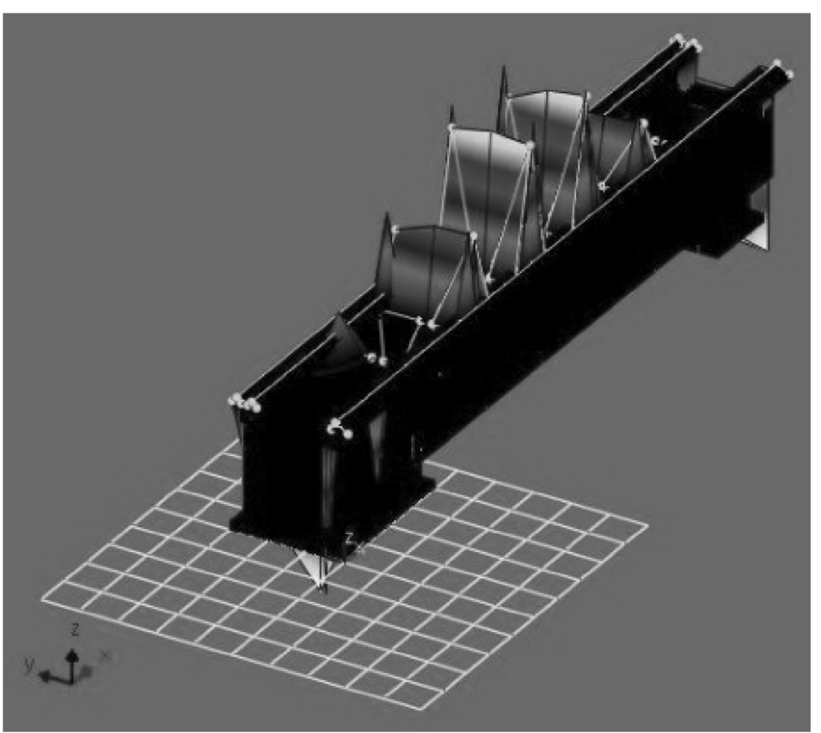

Fig. 11 Mode for frequency $322 \mathrm{~Hz}$ (experimental modal analysis)

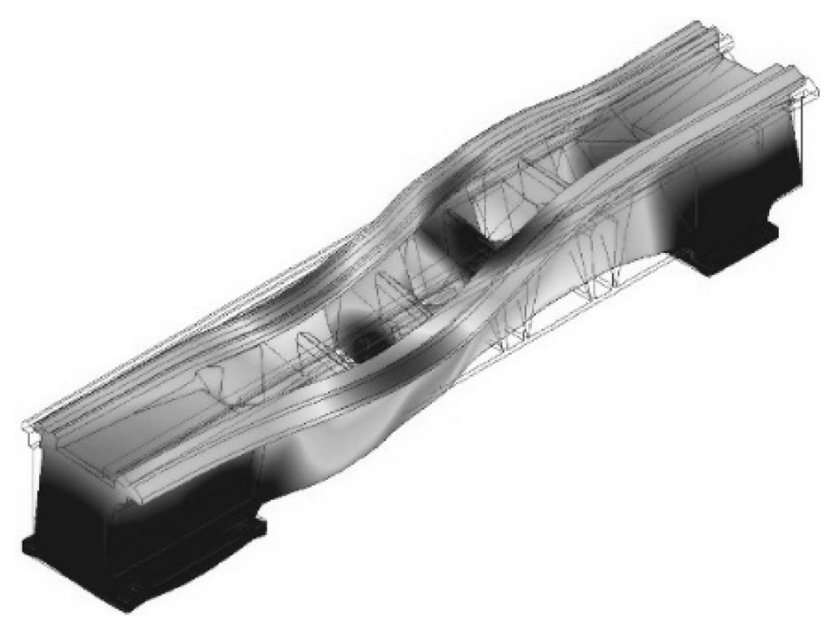

Fig. 12 Mode of frequency $393 \mathrm{~Hz}$ (theoretical modal analysis)

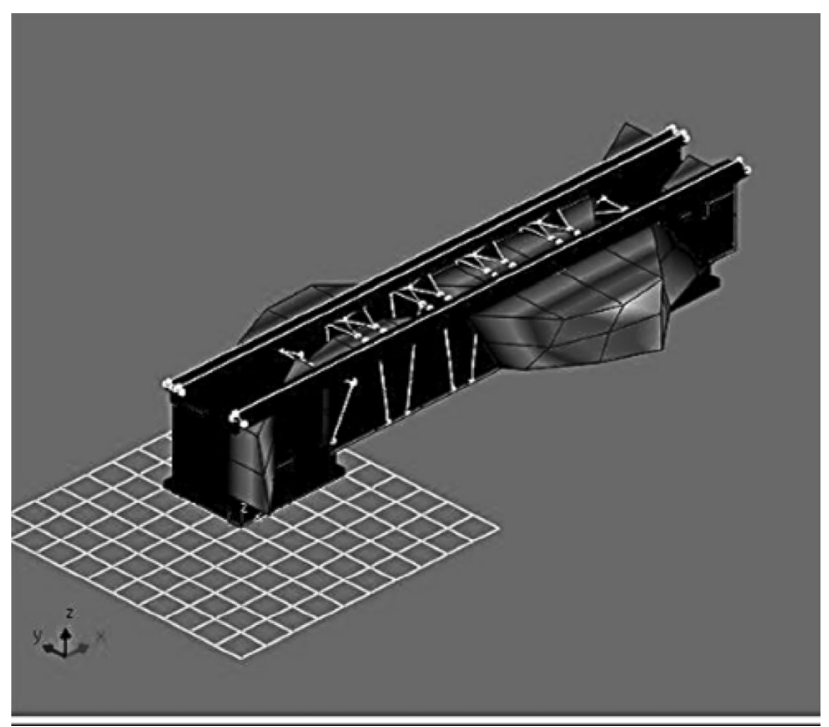

Fig. 13 Mode of frequency $365 \mathrm{~Hz}$ (experimental modal analysis)

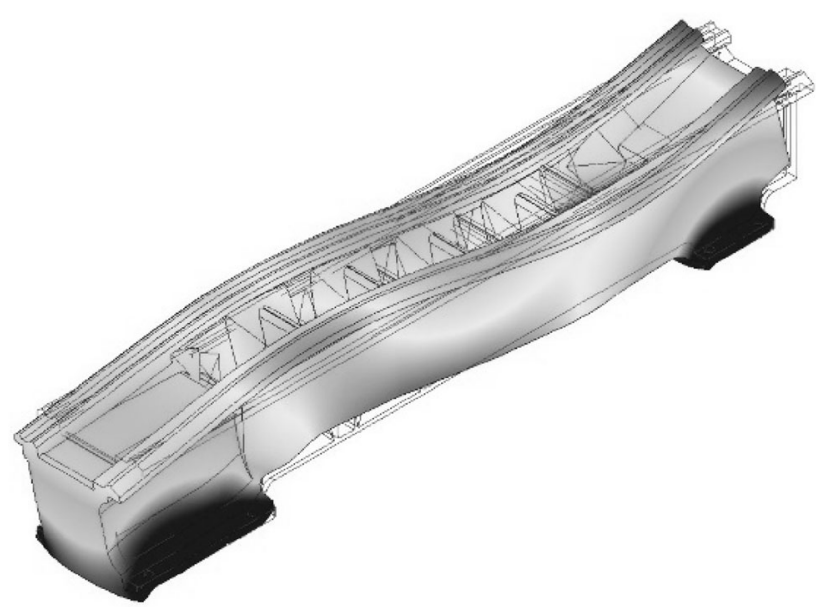

Fig. 14 Mode of frequency $477 \mathrm{~Hz}$ (theoretical modal analysis)

For the first mode represented as one half-wave in transversal direction, the relative error between the theoretical and experimental result reached $10.4 \%$. The highest difference in results was observed at the second mode (one half-wave in vertical direction) where the relative error was $11.5 \%$. For the third mode, the difference in results achieved $7.1 \%$. For the fourth mode, relative error was $9.8 \%$. The smallest difference was obtained for the fifth mode (three half-waves in transversal direction) where it reaches $1.2 \%$ when for the last mode it was $4.0 \%$. The first two modes of vibration are characterized by the highest level of the relative error. It can be explained by the fact that during experimental examination of the real object, the measurements of the modes of low frequency are more susceptible to noise than in the case of measuring modes of higher frequency. Low-frequency modes are more prone to be excited by both the measured excitation force and by not 


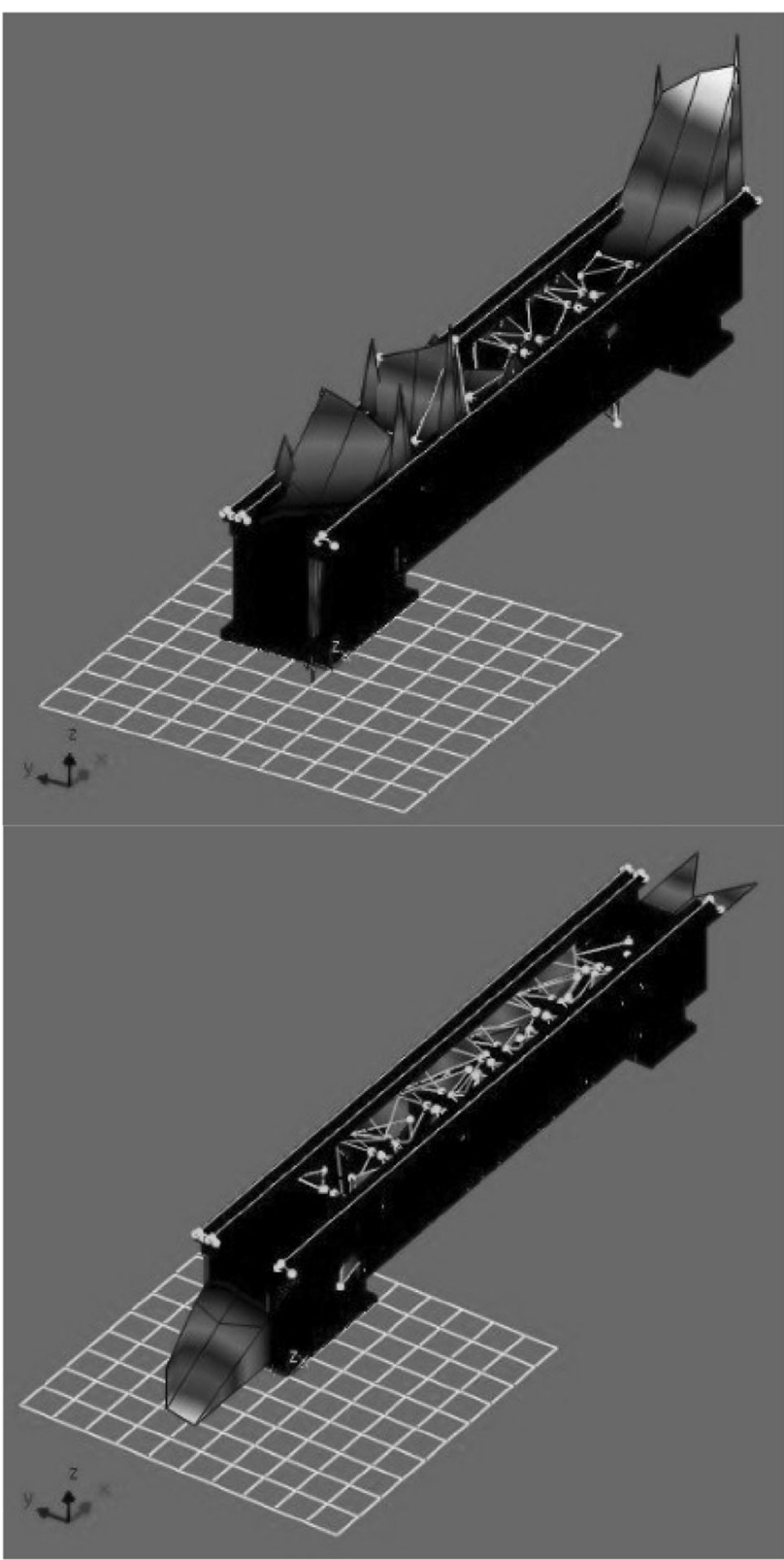

Fig. 15 Mode of frequency $529 \mathrm{~Hz}$ (experimental modal analysis)

measured force influences from the surroundings (noise in the output measurement).

\section{Conclusions}

During the research, the theoretical and experimental modal analyses of lathe bed were conducted. The analyses were carried out in order to compare the dynamic properties results which were achieved in simulation and experiment. The obtained results show the high convergence. For all modes, the relative error of results was from 1.2 to $11.5 \%$. So high convergence of results proves that

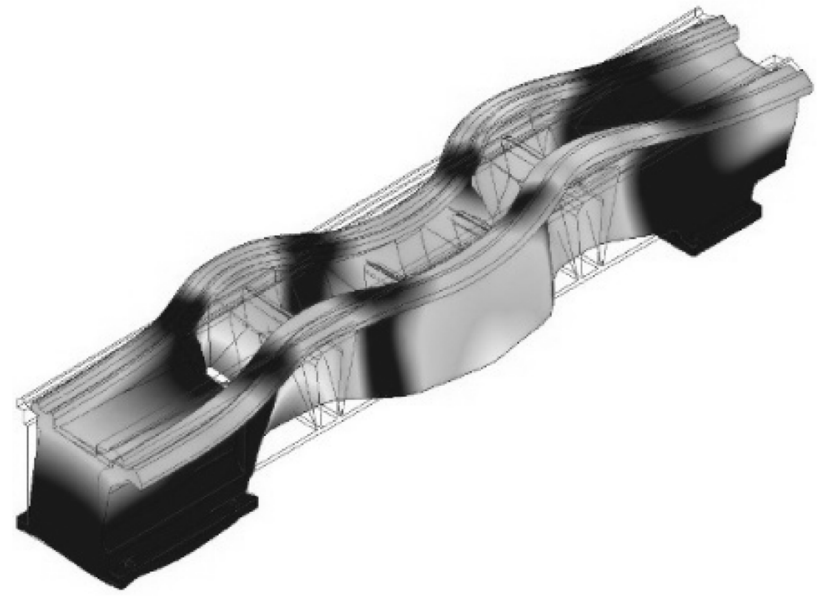

Fig. 16 Mode of frequency $765 \mathrm{~Hz}$ (theoretical modal analysis)

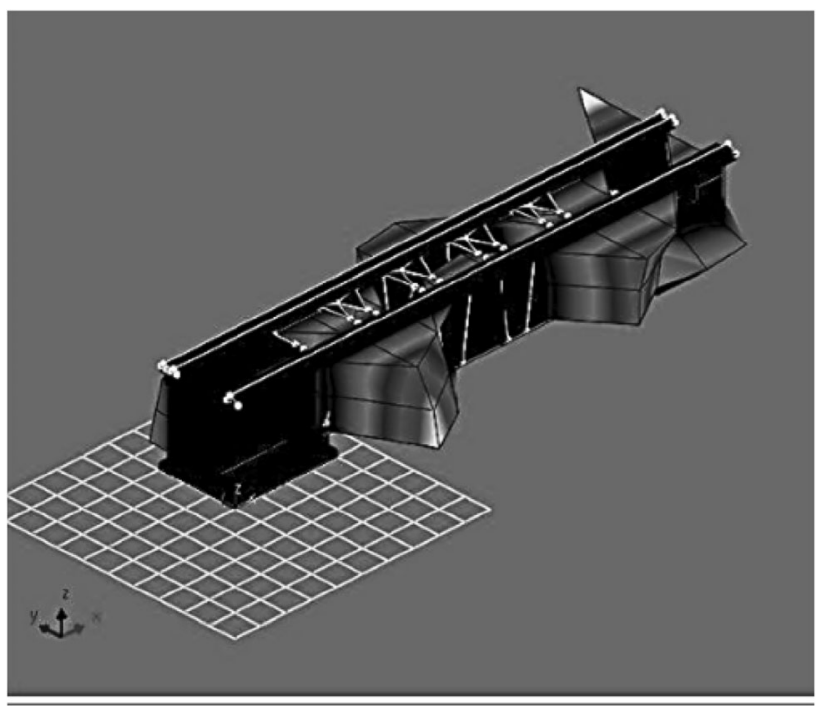

Fig. 17 Mode of frequency $756 \mathrm{~Hz}$ (experimental modal analysis)

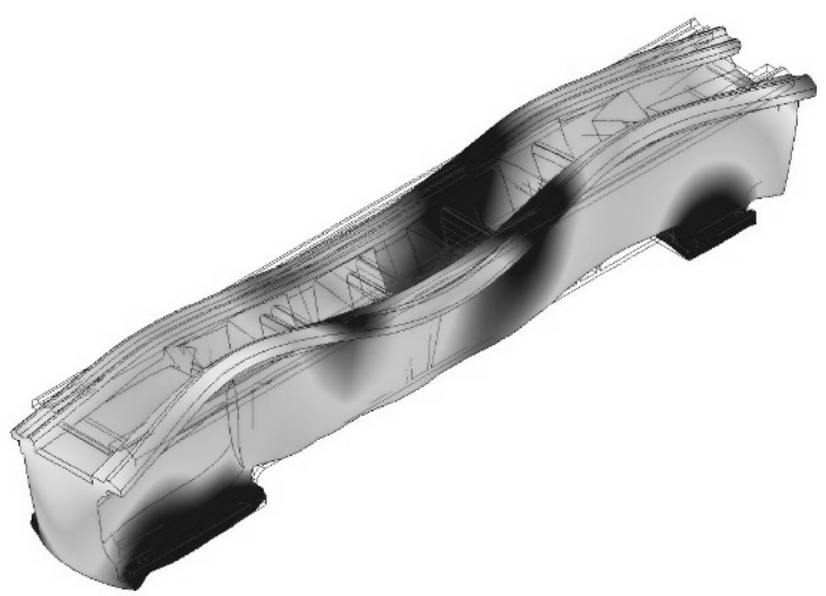

Fig. 18 Mode of frequency $1016 \mathrm{~Hz}$ (theoretical modal analysis) 


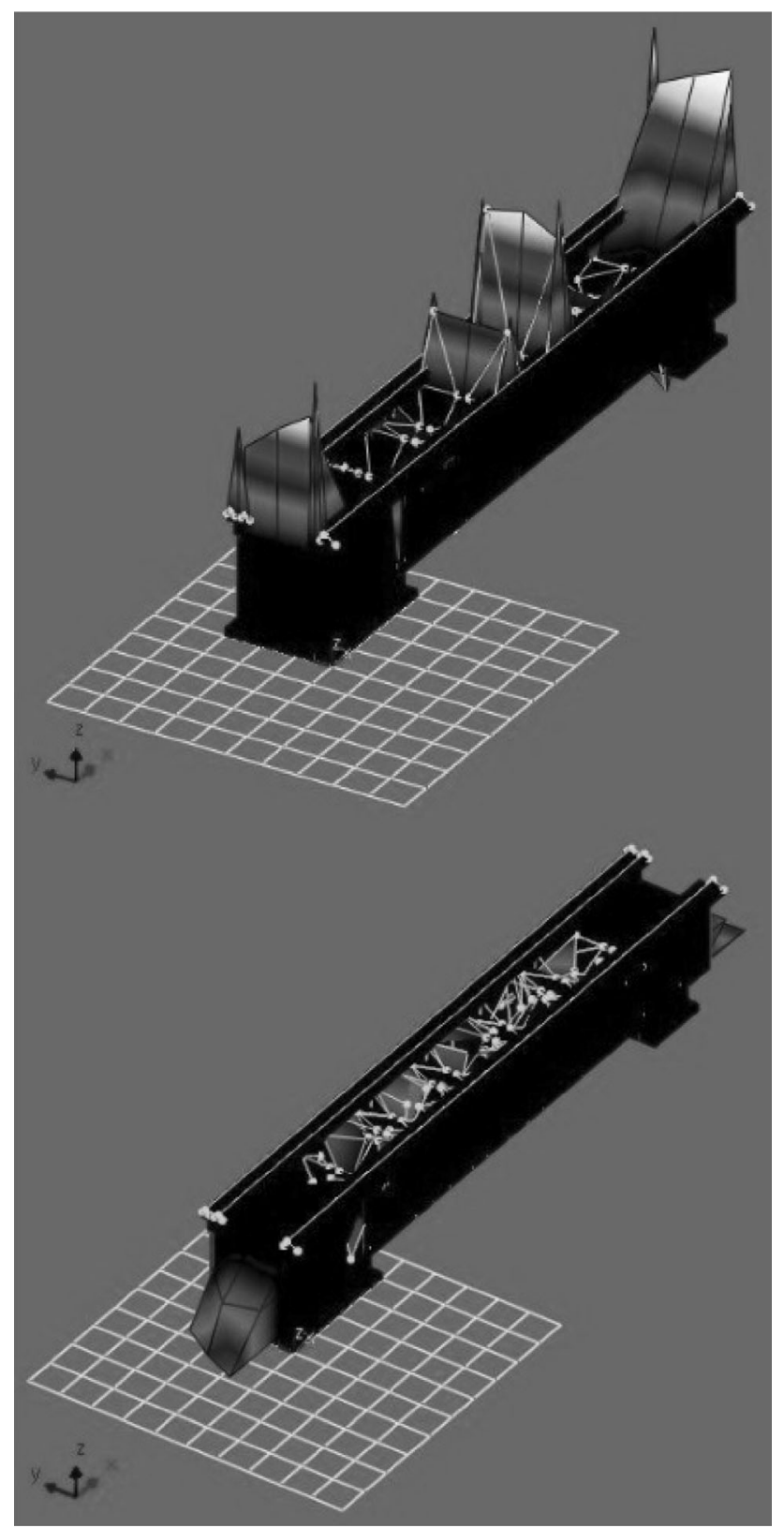

Fig. 19 Mode of frequency $975 \mathrm{~Hz}$ (experimental modal analysis)

Table 6 Comparison of theoretical and experimental research

\begin{tabular}{llll}
\hline Mode & $\begin{array}{l}\text { Theoretical analysis } \\
(\mathrm{Hz})\end{array}$ & $\begin{array}{l}\text { Experimental analysis } \\
(\mathrm{Hz})\end{array}$ & $\begin{array}{l}\text { Error } \\
(\%)\end{array}$ \\
\hline 1 & 189 & 211 & 10.4 \\
2 & 364 & 322 & 11.5 \\
3 & 393 & 365 & 7.1 \\
4 & 477 & 529 & 9.8 \\
5 & 765 & 756 & 1.2 \\
6 & 1016 & 975 & 4.0 \\
\hline
\end{tabular}

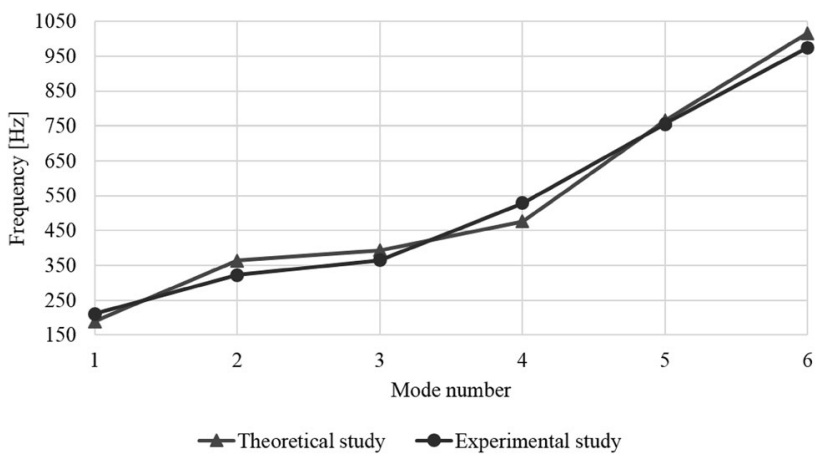

Fig. 20 Comparison diagram of results

properties of the material subjected to theoretical analysis were defined very precisely. Moreover, the high accuracy of mapping the shape of the machine tool in the form of spatial simulation model was achieved. The results also confirm the properly adopted way of splitting the 3D model into finite elements during FEM meshing. Thanks to the conducted experimental verification of the simulation results, it can be said that the simulation results are reliable. Simulations of the dynamic behavior of the object under different load conditions can be successfully based on the verified digital prototype, and they can be performed without further extensive experimental studies.

Open Access This article is distributed under the terms of the Creative Commons Attribution 4.0 International License (http://creative commons.org/licenses/by/4.0/), which permits unrestricted use, distribution, and reproduction in any medium, provided you give appropriate credit to the original author(s) and the source, provide a link to the Creative Commons license, and indicate if changes were made.

\section{References}

Barzegar R, Mahboubkhah M, Ettefagh MM (2013) A study on modal parameters of cylindrical grinding machine structure through experimental test and FEM. Appl Mech Mater 307:275-278

Brecher C, Baumler S, Guralnik A (2014) Experimental modal analysis using a tracking interferometer. CIRP Ann-Manuf Technol 63(1):345-348

Chomette B, Carrou J-L (2015) Operational modal analysis applied to the concert harp. Mech Syst Signal Process 56-57:81-91

Ebrahimi R, Esfahanian M, Ziaei-Rad S (2013) Vibration modeling and modification of cutting platform in a harvest combine by means of operational modal analysis (OMA). Measurement 46(10):3959-3967

Gagnol V, Le T-P, Ray P (2011) Modal identification of spindle-tool unit in high-speed machining. Mech Syst Signal Process 25(7):2388-2398

Kostyleva LV, Palatkina LV, Il'inskii VA (2008) Gray cast iron primary structure detachment crack propagation resistance. Met Sci Heat Treat 50(5-6):248-251

Li B, Cai H, Mao X, Huang J, Luo B (2013) Estimation of CNC machine-tool dynamic parameters based on random cutting excitation through operational modal analysis. Int $\mathbf{J}$ Mach Tools Manuf 71:26-40 
Lopez de Lacalle LN, Lamikiz A (2009) Machine tools for high performance machining. Springer, Berlin

Mahboubkhah M, Pakzad S, Arasi AG, Ettefagh MM (2017) Modal analysis of the vertical moving table of 4-DOF parallel machine tool by FEM and experimental test. J Vibroeng 19(7):5301-5309

Matsuo M, Yasui T, Inamura T, Matsumura M (1986) High-speed test of thermal effects for a machine-tool structure based on modal analysis. Precis Eng 8:72-78

Nangolo NF, Soukup J, Rychlikova L, Skocilas J (2014) A combined numerical and modal analysis on vertical vibration response of railway vehicle. Procedia Eng 96:310-319

Park JB, Choi Y, Lee S-J, Park N-CH, Park K-S, Park Y-P, Park CH-I (2014) Modal characteristic analysis of the APR1400 nuclear reactor internals for seismic analysis. Nucl Eng Technol 46(5):689-698

Pedrammehr S, Farrokhi H, Khani Sheykh Rajab A, Pakzad S, Mahboubkhah M, Ettefagh MM, Sadeghi MH (2012) Modal analysis of the milling machine structure through fem and experimental test. Adv Mater Res 383-390:6717-6721

Rahmatalla S, Hudson K, Liu Y, Eun HCh (2014) Finite element modal analysis and vibration-waveforms in health inspection of old bridges. Finite Elem Anal Des 78:40-46

Vivo A, Brutti C, Leofanti J (2013) Modal shape identification of large structure exposed to wind excitation by operational modal analysis technique. Mech Syst Signal Process 39(1-2):195-206

Zaghbani I, Songmene V (2009) Estimation of machine-tool dynamic parameters during machining operation through operational modal analysis. Int J Mach Tools Manuf 49(12-13):947-957

Zhang GP, Huang YM, Shi WH, Fu WP (2003) Predicting dynamic behaviours of a whole machine tool structure based on computer-aided engineering. Int $\mathrm{J}$ Mach Tools Manuf 43:699-706

Żółtowski B (2002) Badania dynamiki maszyn (dynamics of machines investigation). Wydawnictwo MAKAR, Bydgoszcz 